\title{
A Critical Approach to the NGOs Law in Israel: Social and Economical Perspectives
}

\author{
Javier Simonovich $^{1, *}$, Ofer Arian ${ }^{2}$, Moshe Sharabi ${ }^{3}$ \\ ${ }^{1}$ Department of Human Services, Yezreel Valley College, Israel \\ ${ }^{2}$ Department of Political Science, Yezreel Valley College, Israel \\ ${ }^{3}$ Department of Sociology, Yezreel Valley College, Israel
}

\begin{abstract}
The NGO (Non-Governmental Organization) Law passed by the Israeli Knesset in 1980 replaced the Ottoman law prevailing in place since 1909 (The Amutot Law, 1980). Since its enactment, the NGO Law oversees the activities and administration of more than thirty thousand NGOs in Israel. This essay presents a critical approach of the NGO Law and the social and economic impact on the third sector in Israel in three different areas in the context of the NGOs organizations. The first area relates to the procedures for setting up the organization and defining the goals of the organization. The second area will address the NGO's mandatory institutions and ways of functioning, and alights fields that are not treated in the law institutions and suggests needed solutions that should been included in the law. The third area deals with the concept of "transparency" of the law spread in five incrementing stages that complement each other to achieve total public transparency. Finally, suggestions will be presented for improving the effectiveness of the NGO Law achieving social goals.
\end{abstract}

Keywords NGOs, Legal Aspects, Transparency, Accountability, Third Sector Management

\section{Introduction}

The Israeli "Amutot" (NGO's) Law was promulgated in 1980 by the Israeli parliament, the "Knesset," replacing the Ottoman Law of 1909. It was signed by three pillars of contemporary Israeli politics: Yitzhak Navon (President of the State of Israel), Menahem Begin (Prime Minister), and Yosef Burg (Minister of Interior). The law was passed after the momentous political change in Israel's government when the Likud party, headed by Menahem Begin, won the elections in 1977 and replaced the Labor party for the first time since the founding of the state in 1948. Since its enactment, this law has been guiding and regulating the operations and administration of more than 30,000 non-government organizations in Israel. In nine chapters, seventy-one articles, three amendments (added in 1996 and 2007), and eleven corrections (the last one in 2008), the law describes in detail the steps that an Amuta must follow from its founding, through its daily management, to the submission of annual financial reports, and includes instructions about the dismantling and final dissolution of the Amuta.

This article presents a critical approach to the Amutot Law while taking into consideration the basic ideological concepts that motivated its enactment, and its social and economic impact on not-for-profit organizations in Israel, also known as the third sector (after the business and public sectors). Finally, some suggestions will be offered to help improve the effectiveness of this important law.

The article focuses on three different aspects of the law and an Amuta's life cycle. The first section discusses the procedures for establishing an Amuta and the manner in which its goals are defined. The second refers to the mandatory institutions defined by the law, which every Amuta must set up, their significance and functions, while paying particular attention to the absence of other institutions and functions that could improve the achievement of the law's objectives. Finally, the third section deals with the concept of "transparency" as reflected in the five steps delineated by the law for obtaining the required maximum public transparency. I have called this "Jacob's ladder," since, as in his dream, it connects earth with heaven - the existing terrestrial situation with an anticipated heavenly future.

\section{General Background on Non-Governmental Organizations}

The transparency, accountability and professional level question of NGOs has been approached broadly around the world in many countries. Just at the turn of the Century, Smillie (1997) refers to the need of defining the organizational requirements for transparency and accountability of NGOs that are working in collaboration 
with US government funded projects or UN related NGOs. Smillie (1997) presented three main questions that should be addressed: the costs of the NGOs operation, the evaluation of the NGOs performance and the quality control of their provided services, and accountability. Although everybody calls for greater transparency it is known that annual financial statements revel only a partial picture of the NGOs situation since there is a broad variety of requirements according to the different laws in each country. However, the conclusions are promising, setting a path to improving the administration of NGOs through a change in mind-set, turning evaluation as a tool for improvement rather than control, enhancing accountability to funders and clients, and enabling sustainable development of the civil society. The two concepts addressed, transparency and accountability turns us to the question of what kind of transparency and accountability are we referring? Fox (2007) sustains that transparency can be found in a range of openness from "clear" to "opaque" while accountability can be spread in strength from "soft" to "hard". Since the two concepts overlap, they are different and not necessarily one generates the other.

At the beginning of the 21st Century Lewis (2001) tried to establish a basic framework for the management of NGOs that would fit organizations from different sizes and diverse action areas at local, regional, national and even world-wide scope. He suggested three inter-related areas that NGOs management engaged in: the "organizational domain", "their activities" and "the relationship with other institutional actors" such as government regulators. These three areas encompass the substantial and particular "context" in which the NGO is embedded. Lewis suggests that "At a more general level, creating links between government agencies and NGOs may have implications for strengthening transparency in administration and challenging prevailing top-down institutional culture, both of which may contribute to the strengthening of the wider 'civil society'..."(Lewis, 2001:75). Therefore, the need for transparency should be requested by the official government through promulgation of bills and laws.

But it is not enough to trust on outside legislation and rules. There is also a question of how the NGOs are self-accountable. Lloyd (2005) suggests that there is a traditional accountability through economic and legal rules that sometimes misses some of the stakeholders such as their own clients or the broad public. This perspective sees the budget planning and the economic proportion of the reached goals as main issue to deal within the NGO. Many NGOs have developed organizational self-assessment by creating measures, tools and standards that are applied to themselves. For example, the One World Trust's Global Accountability Project refers to accountability in four dimensions: transparency, participation, evaluation and response mechanisms (Lloyd, 2005). As Irish and Simon (2000) suggest "organizational integrity and transparency of NGOs cannot be promoted by law alone. Guidelines for NGOs are needed that go beyond the law and set higher standards for internal governance and external accountability" (p17). If these presiders will be taken into consideration a transparent NGO will emerge since the incipient stages of policy planning through the different stages of decision-making and implementation of programs and services finally reaching to the self-assessment, evaluation and reporting to all stakeholders. As Lloyd stated "in order for self-regulatory systems to ensure downward accountability, NGOs need to ensure that the type of accountability around which norms and standards are developed is not solely focused on activities such as improving reporting requirements and compliance with laws and regulation, it also need to encompass beneficiary accountability"(p10).

On the above matters, Vaccaro. \& Madsen (2009) suggest managerial and policy improvements through the use of Information and Communication Technologies (ICT) by using it effectively to guarantee internal and external transparency and effective accountability in NGOs. Managers and practitioners should be knowledgeable of technological improvements and opportunities. They also suggest the development of legislative norms set by the public sectors to gain the required level of the desired transparency. Therefore, the Internet can be a very helpful tool in promoting transparency among NGOs. In a study of Spanish NGOs (Gálvez Rodríguez, Caba Pérez, \& López Godoy, 2012) three organizational factors were found significant: "organizational size" measured by the number of volunteers, "public funding" and "organizational age", significantly affect online transparency of Spanish NGOs.

Also in a comparative study between South American NGOs from one side and United States and Europe NGOs on the other side, the authors mention an increasing need for transparency. The Internet is mentioned as one of the best tools to provide accessibility to the general public to the needed information. They found significant differences on the level of control of self-regulated NGOs and the required information on the Internet to provide transparency to organizations that want to be considered as well run (Gálvez Rodríguez, Caba Pérez, \& López Godoy, 2012).

In the last years many organizations of public regulation in Israel were created and they had developed technology used to monitor the activities of NGOs to facilitate the decision making processes of donors, stakeholders and government regulators. For example, the Wise Giving Alliance, "Guidestar" organization, and the National Center for Charitable Statistics (NCCS). These organizations, being NGOs themselves, gather data about NGOs and disperse the information about them in the internet making the information about the organizations accessible as a way to receive recognition and budget allocations (Irvin, 2010).

\section{The Founding of an Amuta (NGO) and Its Goals}

The first article of the law sets down the conditions for the 
founding of an Amuta: "Two or more persons who wish to incorporate as a body corporate for a lawful purpose not aimed at the distribution of profits to its members may establish an Amuta (non-profit society). An Amuta shall be constituted by registration in the Register of Amutot." (The Amutot Law, 1980).

The importance of the law's first article is not what it says, but rather what it does not say. It delineates the economic framework of the law making it clear that Amuta members will not make a profit or distribute revenues among themselves. It provides the basis for the agreement needed to establish an Amuta by defining what its members should not do rather than stating what they should do. In this article, the law separates society's institutions into those that generate profits and those that do not. There is no mention in this introductory statement about the philosophical essence of the law, which is to pursue social welfare and socio-economic justice through the voluntary action of civilians in keeping with neo-liberal, capitalistic ideology. On the contrary, the main concern of this article is to clarify that an Amuta must not engage in the making and distributing of profits among its members, and to regulate the management of the Amuta's income and expenses during any given fiscal year so it does not fail in its fiscal and reporting requirements. This core, established in the first article, guides the development and requirements of the law throughout its seventy-one articles.

The law makes no mention of the social values an Amuta may promote or the nature of its goals in terms of social aims or objectives. In addition, there are no specific stipulations about how the achievements of these objectives should be monitored or evaluated in professional terms. Anyone wishing to learn about the social values upon which the Amutot Law was founded, will be disappointed since none of its seventy-one articles clearly state or define these values, their scope, or the methods for measuring them. Only the Income Tax Order of 1961, article (9)2, can help us find out what social values may be considered as the substance of an Amuta's goals. According to the Tax Exemption article (9)2, only a "public institution" can be exempt from paying income tax. But for a public institution to be recognized as being eligible for such an exemption, it must fulfill a "public goal" related to "religion, education, science, health, social welfare, and sport" for the benefit of the general public good. Thus, the Income Tax Authority, through its legal orders and instructions, provides us with the definition of the basic practical social essence of the Amutot Law, its goals and objectives. Indeed, every Amuta is required, on the basis of this Income Tax Authority article, to obtain from the Authority a Public Institution Certificate, which testifies that it engages in not-for-profit activities and fulfills one of the six public goals mentioned above (see Fig. 1).

In addition, every Amuta is required by law to submit a certificate which testifies that they are a not-for-profit organization (a MALCAR according to the Hebrew acronym). Such certificates are issued by the Value Added Tax (VAT) Authority as stipulated in the VAT law. To be eligible for an exemption from paying VAT (MA'AM) as a not-for-profit organization, the VAT authority stipulates that the organization must be established by a group of people (no specific number is mentioned) whose goal is to carry out non-profit activities on behalf of the general public. The VAT law does not define specific goals (see Fig. 1).

By virtue of this strange state of affairs, the Income Tax Authority defines the public goals, character, and framework of the Amutot Law, and evaluates the manner in which Amutot comply with it. Thus, the public goals of Amutot are evaluated every year by the Income Tax Authority by means of financial reports and accounting tools rather than social, qualitative and quantitative, tools. This situation improved in 2007 with the adoption of the third amendment to article 37(a), which requires every Amuta to submit a descriptive report about their main activities. Nevertheless, the added requirement refers to general, descriptive aspects of the Amuta's activities and additional financial information but fails to establish a detailed, systematic evaluation process including standardized measurements to assess goal achievement

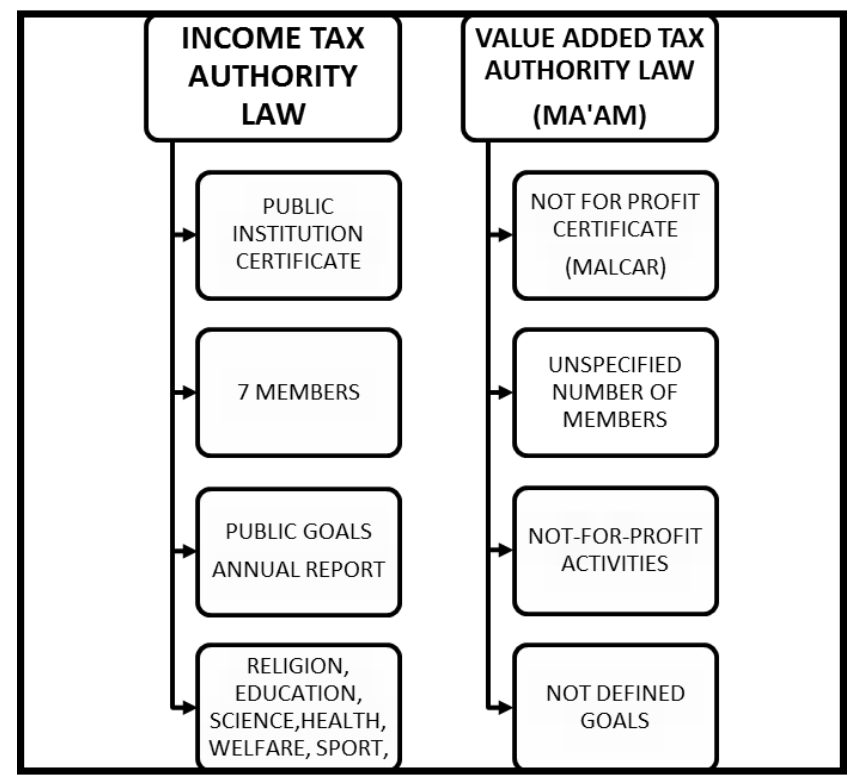

Figure 1. Income Tax Authority and VAT authority certificates required from Amutot.

Besides the requirements mentioned above, the Income Tax Authority demands that a recognized public institution (Amuta) that has public goals and wants tax-exempt status must have at least seven founding members whereas article 1 of the Amutot Law requires only two. Once again an external, financial factor requires public institutions to function according to the Income Tax Authority and not as specified in the Amutot Law. Therefore, historically, the Ministry of Justice's Registrar of Amutot asks every Amuta, on the official Amutot registration forms, for a list of seven founding members, in keeping with the Income Tax Authority requirements, and not two as the Amutot Law demands. On this form, the Registrar urges prospective founders to create a group of seven people during the registration process, not based on a social issue that might 
inspire two people to form an association, but rather due to financial considerations that demand seven individuals.

Another example of focusing on the "don'ts" rather than the "dos" can be seen in article 3 of the law, which clearly states that an association of people will not be registered if it seeks to form an Amuta that includes among its public goals the denial of the existence of the State of Israel or its democratic system, or if there is a basis for suspecting that the Amuta will serve illegal purposes. It is understandable that the law defends the basic values of the existence of the Jewish State and its democratic system. In the same way it would be understandable if the law would specify other social values requirements. Instead, the first chapter goes on and on about various aspects of the formal procedures for establishing the association. The second chapter describes in detail the way the Amuta rules become the contract between the association and its members, and how the rules define their conduct. The first amendment of 1996 goes further, specifying in 21 articles the general rules recommended by the law for adoption by those Amutot that are unable to formulate their own rules. In general, the rules include specific conditions for granting membership in the Amuta, the timetable and democratic conduct of the general meeting, the way to establish and elect the Amuta's board. They also allow the establishment and management of Amuta branches around the country, and even stipulate that the assets remaining after the dissolution of the Amuta must be transferred to another Amuta with similar goals. Thus, once again, the amendments of the Amutot Law take into consideration the "don'ts" for a newly established Amuta and the administrative and financial procedures required up to its dissolution, without establishing the "dos" mandated by clearly defined social goals and standards that can be evaluated.

\section{The Amuta as an Institution}

The fourth chapter of the Amutot Law establishes the mandatory institutions, which every Amuta must have, and their functions. Article 19 determines that every Amuta will have a general meeting, a board, and a control committee. Articles 20-24 provide a detailed explanation of the formal procedures to be followed by the general meeting, articles 25-29 describe the rules of conduct for the board, and articles 30 and 31 dictate the manner in which the control committee is meant to function.

The general meeting should meet at least once a year to make strategic policy decisions, approve the various annual reports of the Amuta, and implement democratic practices by voting for or against any issue related to the Amuta.

The board is actually the committee that governs the routine functioning of the Amuta, in conformance with the policies set down by the general meeting, as mandated by article 27, which establishes that the board members should work for the benefit of the Amuta according to the goals set down in the Amuta's rules and according to the decisions of the general meeting. The board meets as required and acts as the executive body of the Amuta.

The control committee is responsible for verifying from time to time but at least once a year, the fulfillment of the Amuta goals, the proper functioning of the Amuta institutions, and its proper financial management. The Amutot Law permits a Certified Public Accountant (CPA) to fulfill the role and duties of the control committee if required by the law or decided upon by the general meeting. Most of the specified responsibilities of the control committee that appear in the law itself are related to financial and administrative issues.

The law does not require any type of professional supervision for the activities carried out by the Amuta. Its only specific concern is to make sure that public funds and donations are appropriately allocated and used according to proper accounting procedures. An Amuta could receive and spend funds properly without making any social change or improvement, yet, if financial procedures are carried out correctly, it would be considered to be functioning satisfactorily. As previously noted, the law itself contains no definition of social values and goals, while external definitions have been adopted; moreover, it also fails to establish a proper body within the Amuta organization to carry out professional follow up. For example, if an Amuta works in the area of education, helping children succeed in school, it would be inspected by an auditor and or it would have to submit a report compiled according to specific financial methods to demonstrate the proper disbursement of its funds. The law, however, does not stipulate any requirements about recommended pedagogical standards, evaluations, or reports that would show achievements and measure success within the target population.

\section{Jacob's Ladder: Financial Reports and Transparency}

Chapter five describes the legal requirements pertaining to the financial management of the Amuta, the proper procedures for presenting official documents, and the various organizational levels authorized to review the official documents of the Amuta. A careful analysis of the law shows that it created a ladder of transparency starting from a basic, limited group of several people within the Amuta and ending with broad, general public transparency, which allows any citizen to review the official documents of the Amuta (see Fig. 2).

The first rung of this ladder is article 35(a), which mandates that the Amuta must compile and submit financial reports. In the same article, clause (b) grants to any board member, or control committee member, or the CPA, the right to review any financial document and receive from any member of the board or any Amuta employee any file, document or information needed to fulfill their legally 
authorized function. This first rung of the ladder is very important because it suggests that, in regard to the internal matters of the Amuta as a public institution, there are no secrets and all information about these matters should be made known to at least to the members of the Amuta institutions: the members of the board and the control committee, and the professional CPA. As regards this first rung and those that follow, there is no mention of other professional experts who should also be engaged in reviewing Amuta activities.

The second rung of this "Jacob's ladder" of transparency is established by article 36 (a) and (b). Once a year, the board is required to prepare a balance sheet and a financial report that describes the income and expenses of the Amuta during the fiscal year. The report is to be presented to the control committee for assessment and after that it must be approved by the general meeting and sent to the Registrar of Amutot at the Ministry of Justice for revision and final approval. Clause (b) of this article is of major importance for the transparency of an Amuta's activities and proper reporting because it states that the Amuta's annual financial report should include a section that lists the five top executives who receive the highest salaries and benefits. In this way, if the Amuta has paid salaries that exceed the accepted range, it will become immediately obvious to its institutions, which will then be able to take proper steps to avoid the waste or misuse of public funds.

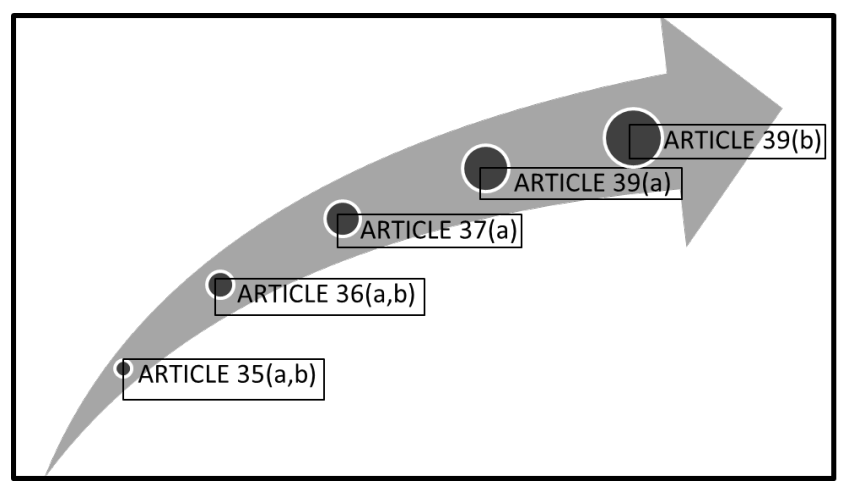

Figure 2. The Transparency Ladder of the Amutot Law

Lately, (on the 21st of December 2015) a further amendment to the article 36(b) was presented to the Knesset (Israel Parliament) to improve transparency regarding private donors. In the case that the donor is an organization or foundation, the amendment requests to cite the identity of the donor including the name, number and the original country. In the case that the donor is an Israeli citizen he is requested to cite his name and ID number. If he is a foreign citizen, he should cite his name, nationality and passport number. The Registrar of Amutot is allowed to make exceptions on the disclosure of the identity donors when applicable, and is required to publish the list of excepted Amutot on the Internet site of the Ministry of Justice. The Registrar of Amutot will report once a year to the Law and Justice Committee of the Knesset the number of special permissions provided and the reasons for the decisions. The objective of the amendment is to increase the transparency concerning the funding of NGOs activities in Israel specially those NGOs that are involved in political activism. The validity of the amendment comes from the public right to open and free information, and tries to find an equilibrium between the NGOs rights to act freely and the right of the Israeli public to know the origin of the NGOs funds.

\section{The Descriptive Report}

In 2007, twenty-seven years after the enactment of the Amutot Law in 1980, a third amendment was added to article 37(a) delineating additional information about Amutot activities, which should be added to the annual financial report. The amendment's demand for a descriptive report the third rung of the ladder of transparency - requires an Amuta to provide, inter alia: a description of the main activities it carried out in pursuit of its objectives; an organizational flowchart that includes the names and job descriptions of each employee; information about how the donations received during the report period were used, including direct and indirect fundraising costs; recommendations about dealing with any deficiencies found by internal or external sources in regard to Amuta activities; a description of any important changes in the target population that may be associated with the Amuta's goals; a description of the geographic area served by the Amuta; and any important events that took place during the reporting period, such as the resignation of the executive director. The third amendment helps ensure the transparency of the Amuta's progress and achievements by making it compulsory to report about them. But once again, the law makes no provision about the suitable professional qualifications of the person responsible for meeting the requirements of third amendment, nor does it recommend standardized measures for describing the goals, target population, or problems addressed by the Amuta.

All the original or authorized copies of reports and documents produced by the Amuta must be submitted to the Registrar of Amutot of the Ministry of Justice after being signed by two members of the board and following the approval of the general meeting. These reports should include, inter alia, any important changes, which occurred during the year such as a change of address or the resignation of the CPA or auditor; the general meeting's authorization of the annual financial reports and the descriptive report. Article 38(a) gives the Registrar of Amutot the power to demand any document or information needed to clarify any matter in the financial report. The wording of the law presents the financial report as the primary document, while making other reports (such as the descriptive report) secondary.

Finally, article 39(a) guarantees the right of any Amuta member to examine the Amuta's membership registration records, the board's registration records, protocols and financial reports presented to the general meeting at any 
reasonable time. This reinforces the concept that there should be no secrets within the Amuta and among its members regarding the general meeting's approved reports. But the law goes beyond transparency within a specific Amuta, moving even further towards total public transparency, by granting, through article 39(b), anyone who asks the right to request from the Registrar of Amutot the approved reports and documents, which have been submitted to it. Furthermore, given the opportunities of cyberspace, where it is possible to be totally open in consideration of public interest issues, the law was updated in 2006 to state, in article 39(c), that essential information about an Amuta will be published on the Internet site of the Ministry of Justice making Amuta matters almost totally transparent. Article 39(c) refers to reports and payments carried out by or due to the Amuta (without mentioning the names of the highest paid employees). The use of cyber media or Information and Communication Technology (ICT) has become a very important tool to guarantee transparency as mentioned by Vaccaro \& Madsen (2009). In an interesting study at the Italian Association of Blind People, they showed that ICTs can be beneficiary to improve and reach internal and external transparency in NGOs which contribute to address better accountability. Therefore, they recommend that managers and policy makers in NGOs should implement the use of ICTs. This interesting conclusion supports the legal required amendment mentioned earlier that facilitates, in a compulsory way, a total transparency legally supported with the help of updated technology.

The "Jacob's ladder" of transparency translates the purpose of the legislators who wrote the law. Any activity performed without the intent of making a profit and to promote social goals should be open and clear to all. Today, therefore, it is unusual to find Amutot that are reluctant to provide information about their activities and financial administration.

\section{Conclusions}

The Amutot Law was promulgated in 1980 as a government and parliamentary effort to give clear and practical guideline to third sector organizations. The law establishes the managerial and administrative principles for Amutot to follow so they conduct themselves properly without risk of misusing public and donor funds. To a great extent, the main concern of the law has remained the proper administration of financial matters while proper attention has not been given to values oriented content, the professional quality of the services provided, and the reliable evaluation of the activities engaged in by the Amuta. It is clear that the law fulfils a noble goal and that if it did not exist, the Knesset and the government would have to pass such a law as soon as possible. It is also clear that the socio-economic and political processes that have taken place in Israel since the inception of the law have justified its enactment and helped the third sector in Israel achieve the status it enjoys today.

Yet the law cannot remain unchanged; it needs to be improved with regard to quality and practical applications. During the thirty years of its existence, some changes and amendments were introduced did improve the application of the law; however, further changes and improvements still need to be made, as suggested throughout the present article and presented below. To sum up, the following conclusions may be made:

1. The need to define the goals of the Amuta must be derived from the Amutot Law and separated from the Income Tax Law.

2. The Amutot Law defines three formal institutions that are assigned the task of carefully and judiciously dealing with administrative, management, and financial issues. In the world of the global village, where professionals and organizations are becoming more and more specialized, there is a need for at least one more mandatory Amuta institution, a professional one, to be stipulated by the law.

3. Financial reporting transparency is one of the most important benefits to society of the Amutot Law. All Amutot should function according to the "Jacob's Ladder of Transparency" and make it clear that they have nothing to hide from the public. This transparency should be expanded and relate not only to financial information but also to standards for measuring the achievements of Amuta activities.

4. The third amendment, which was added in 2007 and deals with descriptive reports was an admirable attempt to improve Amuta reports about substance and achievements, but once again it pays less attention to substantive content than to financial procedures. The descriptive report should focus on how goals and objectives are being achieved and provide qualitative and quantitative evaluations.

\section{Suggestions for Improving Third Sector Functioning in Reference to the Amutot Law}

The third sector in Israel has become an important part of Israel's economic and social life. Currently, about 30,000 Amutot serve Israeli society, working in an extremely broad spectrum of social areas. Israel was founded in 1948 as a welfare state, but since then it has turned to the "right" from the economic point of view and become a civil society where individuals have to take care of themselves and others. The government no longer deals with many social areas, leaving a vacuum that has been occupied by concerned citizens who decide to respond to the needs of neglected sectors of the population or promote personal or social ideologies they hold dear. As part of the political changeover from socialist ideology to neo-liberal capitalism, the various governments 
that have been in power since 1977 established a policy of budget cuts and restrictions on allocations for social welfare matters that has resulted in social polarization and increasing inequality. On the other hand, the same policy encourages large firms, foundations, and wealthy individuals to care for the needy and set up not-for-profit organizations to provide the services that are lacking. It seems that this process is irreversible and even reinforced by the government's decision of February 24, 2008, to recognize the third sector and the civil society as full partners in the building of a better society together with the public and business sectors.

Based on the above analysis of various aspects of the Amutot Law and the situation brought about by government policies over the years, it is important to make suggestions for further improving the execution of the Amutot Law.

- Definition of Social Goals: A public goal must be defined according to social welfare standards. The Amutot Law cannot accept a definition formulated solely on the basis of the financial point of view. The time has come to reject the financial definition of the Income Tax Authority and reach an understanding about a hierarchy of the social goals for Israeli society, which should be put into practice. Some areas need to be expanded, while others need to be restricted.

- Definition of Professional Committees: The three mandatory institutions that the Amutot Law established are no long sufficient. In an era of professional specialization, the law should consider setting up an Amuta committee composed of professionals with suitable background and authority. This committee will be in charge of developing qualitative measurements suitable for the social goals in question and creating adequate standards and reports to ensure the successful achievement of the Amuta's goals.

- Amutot Supervision: The proliferation of thousands of Amutot creates an unclear social services environment and overlap between different Amutot that perform the same functions and promote the same goals. Competition among the Amutot is almost unavoidable and this competition diverts the main efforts of the organization from helping people to devising competitive strategy aimed at acquiring supporters for their cause and obtaining the necessary funds. It is particularly important to establish some type of professional supervision for Amutot within the relevant government ministry or department (welfare or education, for example). In this way, it will be possible to ensure a professional approach to the services provided by the Amutot and the quality of the programs provided.

- Qualitative Measurements and Reports: The evaluation of quantifiable data such as budgets and financial management is a strict and very understandable requirement of the law; however, the time has come to add a compulsory qualitative report to those that already exist (the financial and descriptive reports). This could be accomplished by specifying additional content requirements in the descriptive report or by creating standard qualitative reports that every Amuta would be obliged to submit annually in order to continue their activities in the following year. Such a report would be considered an annual renewal of the Amuta's license to carry out their proven successful activities.

- License for NGO Management: In the same way that other organizations have basic qualification requirements for those who aspire to administrative positions, managing an Amuta today requires not only an in-depth understanding of the Amutot Law, but also many administrative skills. Many universities and colleges offer degrees or basic training on the B.A. and even the master's level in the management of not-for-profit organizations. A thorough understanding of the Amutot Law must be made mandatory for all the executive directors and CEOs of the thousands of Amutot operating in Israel and the possibility of creating a basic training course and licensing process, including an examination, for future directors and CEOs should be considered.

\section{REFERENCES}

Fox, J. (2007). The uncertain relationship between transparency and accountability. Development in Practice, 17(4-5), 663-671.

Gálvez Rodríguez, M., Caba Pérez, M., \& López Godoy, M. (2012). Cómo perciben las organizaciones no gubernamentales autorreguladoras la transparencia: Análisis comparativo de Latinoamérica versus Europa y Estados Unidos. Latin American Research Review, 47, 179-202.

Gálvez Rodríguez, M., Caba Pérez, M., \& López Godoy, M. (2012). Determining factors in online transparency of NGOs: A Spanish case study. VOLUNTAS: International Journal of Voluntary and Nonprofit Organizations, 23(3), 661-683.

Irish, L. \& Simon, K (2000) "Law and governance: a lesson in limits", The Journal of Non-Profit Law, Vol2, Issue 3, (on-line version)

http://www.icnl.org/journal/Vol2iss3/Arn_LK.htm

Irvine, R.A. (2010) State regulation of on for profit: Responsibility without obvious results. In Limor, N. (ed.) Regulation: The Third Sector. Tel Aviv, Hakibutz Hameuchad. (H)

Lewis, D. (2001). The management of non-governmental development organisations An introduction. London and New York: Routledge.

Smillie, I. (1997). NGOs and development assistance: a change in mind-set. Third World Quarterly, 18(3), 563-578.

Vaccaro, A. \& Madsen, P. (2009). ICT and an NGO: difficulties in attempting to be extremely transparent. Ethics and Information Technology, 11(3), 221-231.

The Amutot Law (1980)

http://www.israelinsurancelaw.com/amutot/amutot-law-1980.html 